\title{
Relationship between Glaucoma Drainage Device Size and Intraocular Pressure Control: Does Size Matter?
}

\author{
${ }^{1}$ Cooper D Rodgers, ${ }^{2}$ Alissa M Meyer, ${ }^{3}$ Mark B Sherwood
}

\begin{abstract}
There is ambiguity in the literature regarding whether a larger glaucoma drainage device (GDD) achieves a lower long-term intraocular pressure (IOP). There is some evidence on both sides, but overall there seems to be an optimal surface area of approximately $200-250 \mathrm{~mm}^{2}$ beyond which there may be little advantage to increasing the plate size for most patients.
\end{abstract}

Keywords: Baerveldt, Glaucoma, Glaucoma drainage device, Intraocular pressure, Molteno, Retrospective study, Visual acuity.

How to cite this article: Rodgers CD, Meyer AM, Sherwood MB. Relationship between Glaucoma Drainage Device Size and Intraocular Pressure Control: Does Size Matter? J Curr Glaucoma Pract 2017;11(1):1-2.

Source of support: Nil

Conflict of interest: None

\section{INTRODUCTION}

Over the years, there has been a lack of clarity in the literature regarding the relationship between glaucoma drainage device (GDD) size and intraocular pressure (IOP) control. An early randomized prospective study by Heuer et $\mathrm{al}^{1}$ suggested that the double plate Molteno $\left(270 \mathrm{~mm}^{2}\right)$ provided better IOP control than the single plate $\left(135 \mathrm{~mm}^{2}\right)$ at 1 to 2 years postoperative. A later paper by Britt et $\mathrm{al}^{2}$ demonstrated that a larger implant is not necessarily better than a smaller one; the Baerveldt $350 \mathrm{~mm}^{2}$ was superior to the Baerveldt $500 \mathrm{~mm}^{2}$ in regulating IOP. Does this mean that there is an optimal implant size? In a number of prospective randomized controlled studies, the Baerveldt $350 \mathrm{~mm}^{2}$ has been the default implant. The tube vs trabeculectomy (TVT) and the primary tube $v$ s trabeculectomy (PTVT) study groups ${ }^{3}$ utilized this implant in a comparison of tube shunt surgery and trabeculectomy with mitomycin C (MMC).

In the Ahmed-Baerveldt comparison $(\mathrm{ABC})$ and Ahmed vs Baerveldt (AVB) studies, ${ }^{4,5}$ groups compared the silicone Baerveldt $350 \mathrm{~mm}^{2}$ with the silicone Ahmed

\footnotetext{
${ }^{1,2}$ Research Assistant, ${ }^{3}$ Professor

${ }^{1-3}$ Department of Ophthalmology, University of Florida Gainesville, Florida, USA

Corresponding Author: Mark B Sherwood, Professor Department of Ophthalmology, University of Florida, Gainesville Florida, USA, Phone: +3522738777, e-mail: sherwood@ufl.edu
}

FP7 glaucoma valve $\left(184 \mathrm{~mm}^{2}\right)$. These two studies showed that the Baerveldt $350 \mathrm{~mm}^{2}$ implant offered superior IOP control, but it is still unclear if this is because of the difference in size of the implants or whether it is related to the fact that the aqueous is delayed in getting to the episcleral plate area with the Baerveldt for about 6 weeks postoperative compared with immediate plate delivery with the Ahmed.

There has been some evidence of increased postoperative diplopia with large implants, ${ }^{6}$ and the Baerveldt was modified in the late 1990s by making fenestrations in the plate in order to lower the height of the bleb. This was achieved by allowing fibrous plugs to grow through these fenestrations, connecting the capsule below and above the plate. The wings of the Baerveldt $350 \mathrm{~mm}^{2}$ implant are generally placed underneath two of the recti muscles, which often requires mechanical hooking and manipulation of the muscles at surgery. In the TVT study group, the incidence of diplopia in the $350 \mathrm{~mm}^{2}$ Baerveldt group was $5 \%$ (5 patients) at 1 year.

There have been several small retrospective studies that have compared the Baerveldt $250 \mathrm{~mm}^{2}$ and Baerveldt $350 \mathrm{~mm}^{2}$ implants. A 2003 study by Seah et $\mathrm{al}^{7}$ reported that there were no statistically significant differences in success rate, complication rate, final IOP, visual acuity (VA), and number of medications between the 350 and $350 \mathrm{~mm}^{2}$ implant groups in Asian eyes at a mean followup of 33.4 months. Similarly, in 2015, Allan et $\mathrm{al}^{8}$ found no significant differences between the two implant sizes at a mean follow-up of 40 months.

In our study, ${ }^{9}$ we have compared the larger Baerveldt $350 \mathrm{~mm}^{2}$ implant to the Baerveldt $250 \mathrm{~mm}^{2}$ and the Molteno 3 (245 and $230 \mathrm{~mm}^{2}$ ) implants, all of which are placed in a single quadrant. Like previous studies, our study found no significant difference in mean IOP, medication use, or VA change between the larger $350 \mathrm{~mm}^{2}$ and the medium 230 to $250 \mathrm{~mm}^{2}$ implants.

In conclusion, there does not seem to be good evidence that suggests there are any advantages in using the $350 \mathrm{~mm}^{2}$ Baerveldt over smaller 230 to $250 \mathrm{~mm}^{2}$ GDDs and, at up to 3 years postoperative, the IOP, VA, and medication use appear similar.

\section{REFERENCES}

1. Heuer DK, Lloyd MA, Abrams DA, Baerveldt G, Minckler DS, Lee MB, Martone JF. Which is better? One or two? A randomized clinical trial of single-plate versus double-plate Molteno 
implantation for glaucomas in aphakia and pseudophakia. Ophthalmology 1992 Oct;99(10):1512-1519.

2. Britt MT, LaBree LD, Lloyd MA, Minckler DS, Heuer DK, Baerveldt G, Varma R. Randomized clinical trial of the 350- $\mathrm{mm}^{2}$ versus the $500-\mathrm{mm}^{2}$ Baerveldt implant: longer term results: is bigger better? Ophthalmology 1999 Dec;106(12):2312-2318.

3. Gedde SJ, Schiffman JC, Feuer WJ, Herndon LW, Brandt JD, Budenz DL. Tube versus trabeculectomy study group. Treatment outcomes in the tube versus trabeculectomy (TVT) study after five years of follow-up. Am J Ophthalmol 2012 May;153(5):789-803.e2.

4. Budenz DL, Barton K, Gedde SJ, Feuer WJ, Schiffman J, Costa VP, Godfrey DG, Buys YM, Ahmed Baerveldt. Comparison study group. Five-year treatment outcomes in the Ahmed Baerveldt comparison study. Ophthalmology 2015 Feb;122(2):308-316.

5. Christakis PG, Tsai JC, KalenakJW, Zurakowski D, Cantor LB, Kammer JA, Ahmed II. The Ahmed versus Baerveldt study: three-year treatment outcomes. Ophthalmology 2013 Nov;120(11):2232-2240.

6. Lloyd MA, BaerveldtG, Fellenbaum PS, Sidoti PA, Minckler DS, Martone JF, LaBree L, Heuer DK. Intermediate-term results of a randomized clinical trial of the 350 - versus the $500-\mathrm{mm}^{2}$ Baerveldt implant. Ophthalmology 1994 Aug;101(8):1456-1463; discussion 1463-1464.

7. Seah SK, Gazzard G, Aung T. Intermediate-term outcome of Baerveldt glaucoma implants in Asian eyes. Ophthalmology 2003 May;110(5):888-894.

8. Allan EJ, Khaimi MA, Jones JM, Ding K, Skuta GL. Longterm efficacy of the Baerveldt $250 \mathrm{~mm}^{2}$ compared with the Baerveldt $350 \mathrm{~mm}^{2}$ implant. Ophthalmology 2015 Mar;122(3): 486-493.

9. Meyer A, Rodgers CD, Rosenberg N, Webel A, Sherwood M. Retrospective comparison of large $350 \mathrm{~mm}^{2}$ glaucoma drainage implants to medium-sized $230-250 \mathrm{~mm}^{2}$ implants. J Curr Glaucoma Pract 2017;11(1):1-8. 